\title{
Making Water Work: An Energy Head Equation Demonstration
}

\section{Major Ruth Abigail Mower, United Stated Military Academy, Department of Geography and Environmental Engineering}

MAJ Mower is an Engineer officer with tactical and operational experience in multiple units which participated in three deployments in support of Operation Iraqi Freedom, and one for Operation Atlantic Resolve. Her most recent assignment was as the 553rd Engineer Detachment/Forward Engineer Support Team - Advanced (FEST-A) Commander that is part of the U.S. Army Corps of Engineers' North Atlantic Division, New York District. Specifically, the 553rd ensured the provision of multi-functional technical engineering capabilities such as: limited engineering design; engineer reconnaissance; construction planning and management; base camp development; and geospatial, construction contract, security engineering, and USACE engineer reach-back support. Previously, she served as the 169th Engineer Battalion Executive and Operations Officer over five companies and two detachments within TRADOC that trained 3,500 Soldiers and Non-Commissioned Officers as well as 1,200 Sister Service personnel in over 300 classes per year at five different geographic locations. Her research interests include the how environmental policy, both at the international and domestic levels, results from or intersects with environmental technologies. MAJ Mower teaches EV350 and EV450, required courses for cadets in the environmental engineering sequence.

\section{Major Erick Martinez P.E., U.S. Military Academy}

Erick Martinez is a Major in the United States Army and an Assistant Professor in the Department of Chemistry \& Life Science at the United States Military Academy. He is a 2007 graduate of the United States Military Academy with a B.S. in Environmental Engineering and a 2016 graduate of the University of Florida with an M.E. in Environmental Engineering. He is a registered Professional Engineer (P.E.) in the State of Florida and teaches General Chemistry, Environmental Engineering for Community Development, Environmental Science, and Environmental Engineering Technologies.

\section{Lt. Col. Landon M Raby P.E., United States Military Academy}

LTC Raby is an Engineer officer with experience within both US Army Corps of Engineers and within Combat Units at the battalion, brigade, district, task force and corps levels. His experiences include four operational engineer assignments in support of Operation Enduring Freedom and one engineer assignment in support of Operation Joint Guardian. His research and teaching interests are in master planning, water resources, sustainable LEED design, program and project management. LTC Raby teaches EV450 (Environmental Engineering for Community Development) and EV481 (Water Resources Planning and Design).

\section{Major John Boyle, United States Military Academy, West Point}

MAJ Boyle is an Army Chemical Corps Officer specializing in planning, consequence management, and environmental safety with tactical and operational deployments to Iraq and Afghanistan. His most recent experience was as the 10th Mountain Division Headquarters Battalion Operations Officer with notable operations that include a division headquarters deployment in support of Operation Freedom's Sentinel (Afghanistan) and Division Warfighter iteration 18-01 (Ft. Drum, NY). Previously he served as the 10th Mountain Division plans officer in charge of present and future integration and training of Afghanistan forces in Eastern Afghanistan following two years as a chemical warfare analyst with the Defense Intelligence Agency. His graduate research focused on identifying groundwater underflows in Joshua Tree National Park with focus on the Cottonwood sub-basin.

\section{Lt. Col. Andrew Ross Pfluger, U.S. Military Academy}

Lieutenant Colonel Andrew Pfluger, U.S. Army, is an Assistant Professor and Academy Professor in the Department of Geography and Environmental Engineering at the United States Military Academy. He earned a B.S. in Civil Engineering from USMA, a M.S. and Engineer Degree in Environmental Engineering and Science from Stanford University, and a Ph.D. in Civil and Environmental Engineering from the Colorado School of Mines. He is a licensed PE in the state of Delaware. 


\title{
Making Water Work: An Energy Head Equation Demonstration
}

\begin{abstract}
Gravity-fed water supply systems are vital in providing much of the developing world clean water. To correctly design and implement gravity-fed water systems, engineering students should understand both the continuity and energy equations. However, instead of explaining the energy equation solely through the use of textbooks or slides, a simple in-class demonstration can illustrate the relationships between the elevation head, pressure head, and velocity head terms. A solid understanding of these relationships helps students determine the hydraulic head of a system at any given point by developing a Hydraulic Grade Line (HGL), which is used to understand the capabilities and constraints of a gravity-fed system.
\end{abstract}

\section{Introduction}

The use of models to replicate scaled versions of engineering systems are value added for introductory engineering courses. Specifically, a model that reveals the concept and principles involved in gravity-fed water systems is valuable so students can visualize the direct and inverse relationships of a gravity fed system. The necessity for such a model is driven by the diverse array of disciplines taking these engineering courses as some, if not all students taking the course, do not have an engineering background. Specifically, this model is used in Environmental Engineering for Community Development (EV450), the capstone course of a three-course sequence. Every student at West Point is required to take a core sequence in engineering, but it is not necessarily their major or primary discipline of study. Out of the 40 classes students will take during their four years, the engineering sequence only consists of three courses. There are several disciplines students can choose to take for their sequence to include such as civil engineering, environmental engineering, chemical engineering, and others. The Environmental Engineering sequence is a three-course path that starts with Environmental Science (EV300), progress to Environmental Engineering Technologies (EV350), and concludes with the capstone Environmental Engineering for Community Development (EV450). In EV450, one of the overarching student objectives is to have students solve a complex design problem which is focused on using the principles of gravity-fed water systems to determine an environmentally sustainable solution. In order to promote methods to address learning style 
differences, the existing model is used to enhance the students' learning experience by showing the principles of gravity fed design and how they work rather just explaining them.

\section{Underlying Concepts}

In 1738 Daniel Bernoulli published Hydrodynamics in which he first presented the Bernoulli equation; essentially, Bernoulli determined a way to express the total energy involved in moving a fluid along a streamline by expressing the sum of its kinetic, gravitational, and fluid-pressure sub-components. ${ }^{1}$

$$
p+\frac{1}{2} \rho V^{2}+\gamma z
$$

If the specific weight of the fluid being analyzed is divided through each term of the Bernoulli equation, then an alternate form of the energy equation results where each term has a length and represents a type of head. ${ }^{2}$

$$
\frac{p}{\gamma}+\frac{V^{2}}{2 g}+z
$$

First, the pressure head represented by $\frac{p}{\gamma}$ is the height that a column of the fluid used would have to be in order to produce the pressure $p .^{3}$ Next, the velocity term $\frac{V^{2}}{2 g}$ represents the vertical distance that the fluid would have to fall to reach the velocity, V, from rest. ${ }^{2}$ Finally, the elevation head, $\mathrm{z}$, is the potential energy that the fluid and its particles have.

To simplify the equation, we understand the pressure (p) divided by the specific weight of water $(\gamma)$ is also equal to pressure head $(\Psi)$; both units measured in length [L].

$$
\frac{p}{\gamma}=\Psi
$$

When the pressure head $(\Psi)$ is added to velocity head $\left(\frac{v^{2}}{2 g}\right)$ and elevation head $(z)$ (or the distance above a known datum), the result will be hydraulic head ( $h$ ), measured in [L]. Hydraulic head can therefore be considered, the total distance water will rise in a pipe as a result of the combined pressure, velocity, and elevation head.

$$
h=\Psi+\frac{v^{2}}{2 g}+z
$$


At every point along the system if the hydraulic head was measured, and all the induvial measurements were connected with a line, it would result in the hydraulic grade line (HGL). ${ }^{4}$ The HGL is a useful tool because the elevation difference between it and the ground surface reveals if there are possible high-pressure regions which could burst a pipe, or if there are any low-pressure or even negative pressure areas which may not provide the needed discharge at the tap. The HGL demonstrates the effects of friction as it occurs in the system and can be demonstrated physically by inserting a piezometer at any point within the system and measuring the height of the static water level.

\section{The Physical Model for the Gravity Flow System}

The current demonstration, illustrated in Figure 1, provides an interactive experience with the assistance of three students. The goal for the demonstration is to show how the change in elevation affects the pressure within an open system. Using a simulated reservoir and tap stand with two, two-liter Phipps \& Bird B-KER2 Laboratory Jars and Masterflex Tygon lab tubing to connect both, one student holds the reservoir at a fixed location simulating a water source such as a natural spring, lake, or river, and another student adjusts the elevation of the tap stand using a simulated gate valve from the sampling port of the laboratory jar. As the tap stand location remains lower than the location of the reservoir, students can notice water continuing to flow as the third student is responsible for turning the tap stand valve on and off. However, as soon as the location of the tap stand is higher than the location of the reservoir, water flow stops. Thus, students realize that the location of the outflow must be lower than the location of the inflow assuming there are no pumps in the system.

The next portion of the demonstration is to manipulate the path and elevation of the plastic tubing, which simulates the poly-vinyl chloride (PVC) or galvanized iron (GI) pipe in the gravity-fed system, to confirm if the water will continue to flow. By slightly raising the plastic tubing to form a simulated hill between the reservoir and the effluent most students will assume the water will not flow to the tap stand without a pump since it needs to travel upward. Yet, in this case as the outflow valve is turned on students observe that water does flow as long as the HGL is above the elevation in which is needs to flow over in the (the simulated hill), assuming there are no cracks or leaks in the system. 
Finally, while maintaining the simulated hill from the plastic tubing, when the tap stand is raised above the surface of the reservoir, students notice there is not sufficient energy to raise the water to reach the tap stand and instead negative water pressure exists in the system. Assuming friction loss is negligible, if the effluent tap is not below the influent flow will not occur.

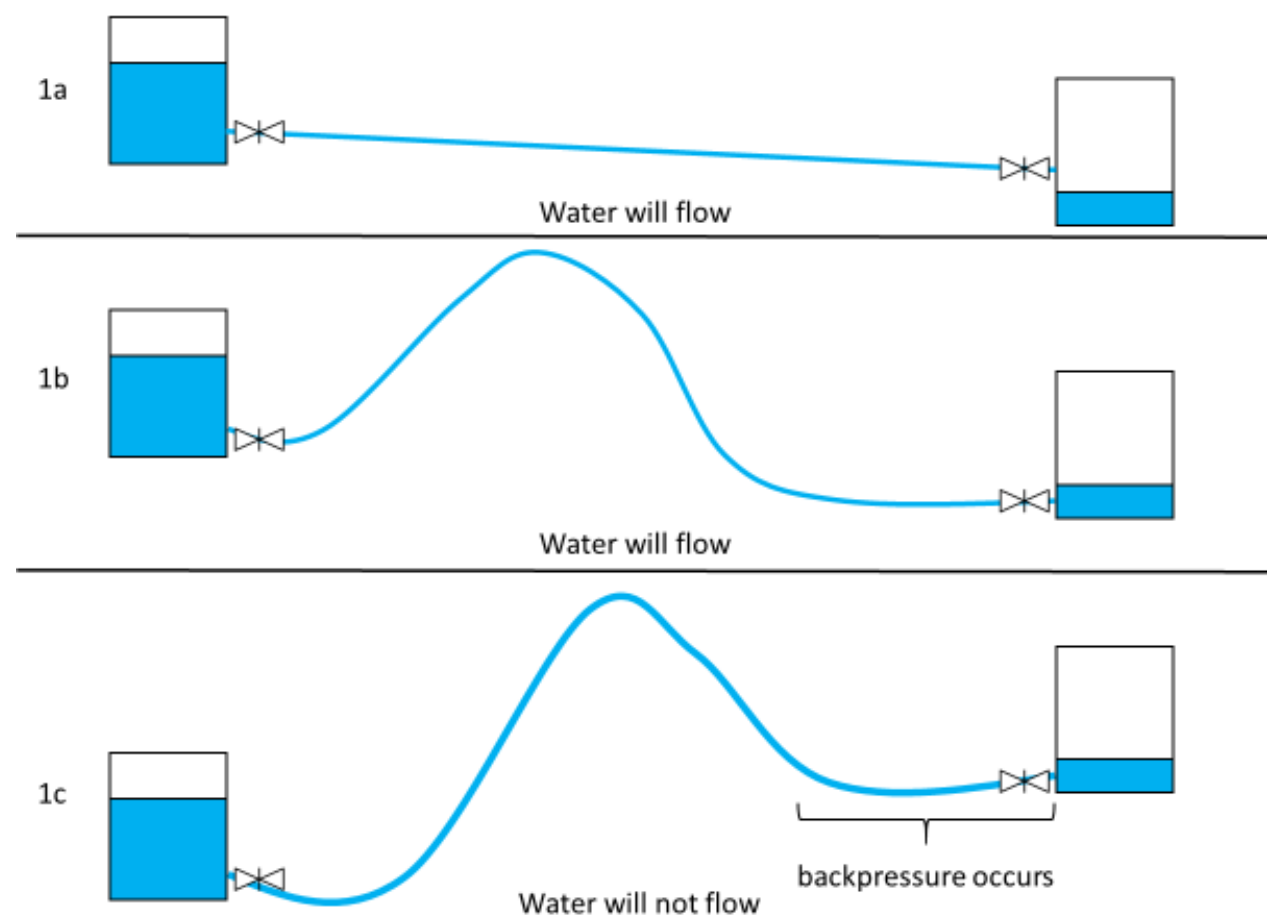

Figure 1. Visual diagram of current demo concept.

\begin{tabular}{|c|c|}
\hline Equipment & Quantity \\
\hline 2L Phipps \& Bird B-KER2 Laboratory Jars & x2 \\
\hline Masterflex Tygon Lab Tubing & x1 \\
\hline
\end{tabular}

Figure 2. Table of equipment needed for current demo concept.

This demonstration helps students visualize pipe flow also in terms of mass balance and introduces how the continuity equation $(\mathrm{Q}=\mathrm{V} \times \mathrm{A})$ plays a pivotal role in understanding what is occurring throughout the system. Since mass is conserved, as water moves through a pipe system (assuming no leaks), mass balance parameters will dictate that the flowrate must remain consistent even as changes of A and V occur. As Q is increased, we must increase the velocity of flow and/or the size of pipe. For a specified Q, flow can be increased by reducing pipe size. 
Conversely, velocity can be decreased by increasing pipe size. Essentially, the continuity equation is just the conservation of mass in terms of volumetric flow. Mass does not appear in the equation though because water is an incompressible fluid, so its density is constant. Written in mass rate terms, continuity is $\rho V_{1} A_{1}=\rho V_{2} A_{2}$. The density, $\rho$, is constant (this model is not operating at extreme pressures), so $\mathrm{V}_{1} \mathrm{~A}_{1}=\mathrm{V}_{2} \mathrm{~A}_{2}$ or $\mathrm{Q}_{1}=\mathrm{Q}_{2}$. Thus, we can equate any two

points in the system, assuming we account for energy losses $\left(\Sigma h_{L}-\right.$ from both friction losses and form losses).

$$
z_{1}+\frac{p_{1}}{\gamma}+\frac{V_{1}^{2}}{2 g}=z_{2}+\frac{p_{2}}{\gamma}+\frac{V_{2}^{2}}{2 g}+\Sigma h_{L}
$$

This allows students to see that at any point along the HGL is truly the sum of the pressure and elevation heads, and the only difference between points would be accounted for by the losses $\left(\Sigma h_{L}\right)$ and demonstrating the potential energy at that specific point physically by piezometers.

\section{Assessment of the Physical Model}

A formal assessment of the impact of the demonstration on student learning was conducted during the fall semester of the 2020 academic year. Of the 212 students enrolled in EV450: Environmental Engineering for Community Development, 193 students responded for a participation rate of $91 \%$. Figure 3 lists five survey questions; data was not collected from the students regarding if the verbal description alone of the equations and material presented above was effective or not prior to the use of the physical model. Overwhelmingly, $73 \%$ of the 193 surveyed students agreed both demonstration and involvement helped them better understand the engineering principles associated with the energy equation. Additionally, $55 \%$ of students also agreed that it was useful to have the demonstration before the class where the energy equation and its related concepts were introduced. A student response included: "it was a good demonstration that helped [me] understand the material...the demo does help." 


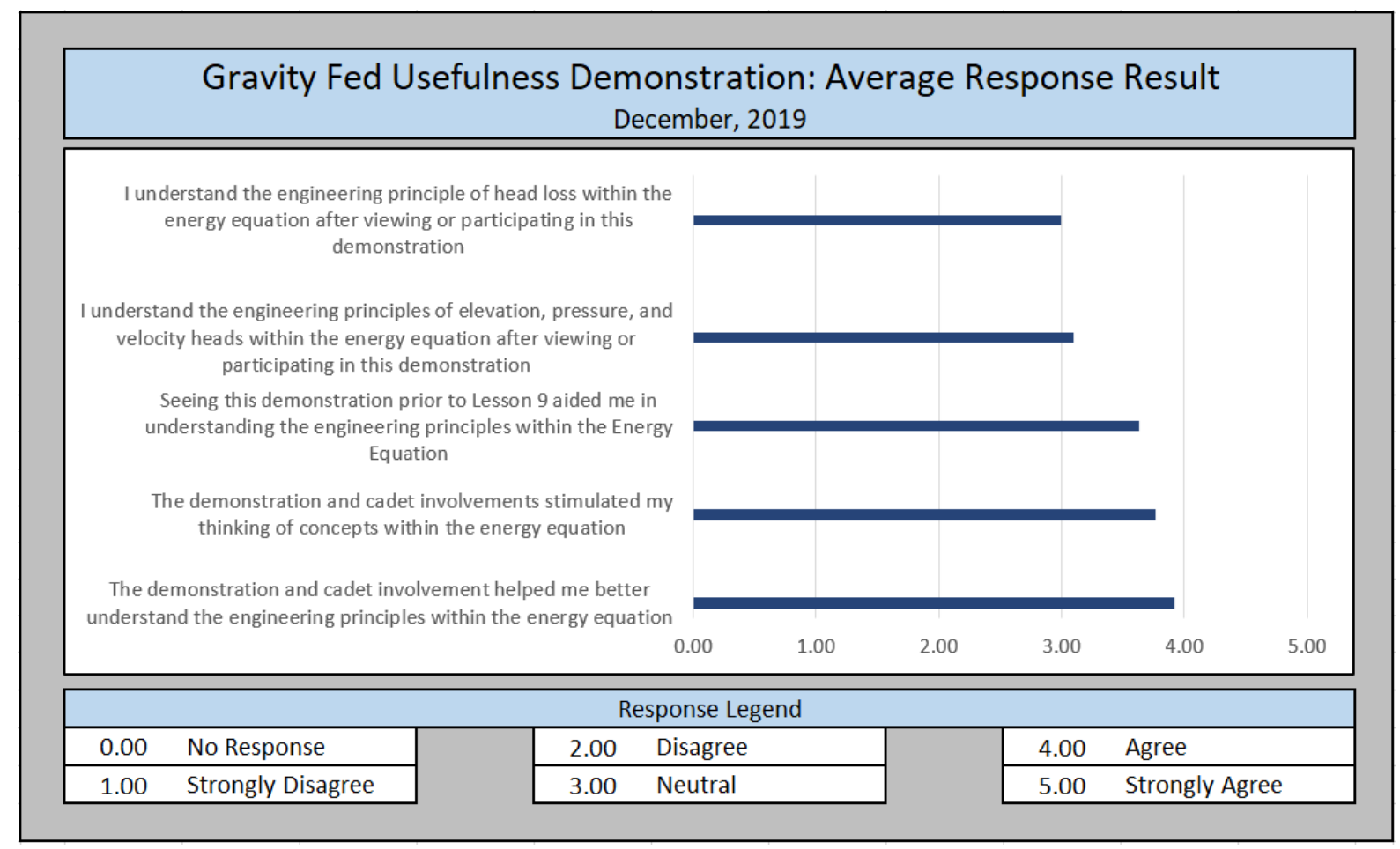

Figure 3. Gravity-Fed in class demonstration usefulness response survey, December 2019.

A separate survey of the 212 enrolled students had 76 students respond by answering questions to determine which learning-style they were most attuned to, and $45 \%$ indicated that they were visual learners who understand and remember material better by sight as indicated by Figure $4 .{ }^{5}$ However, an additional $20 \%$ indicated that visual and audio-learning were equally beneficial to them, thus the majority (65\%) benefit overall from a visual aid. 


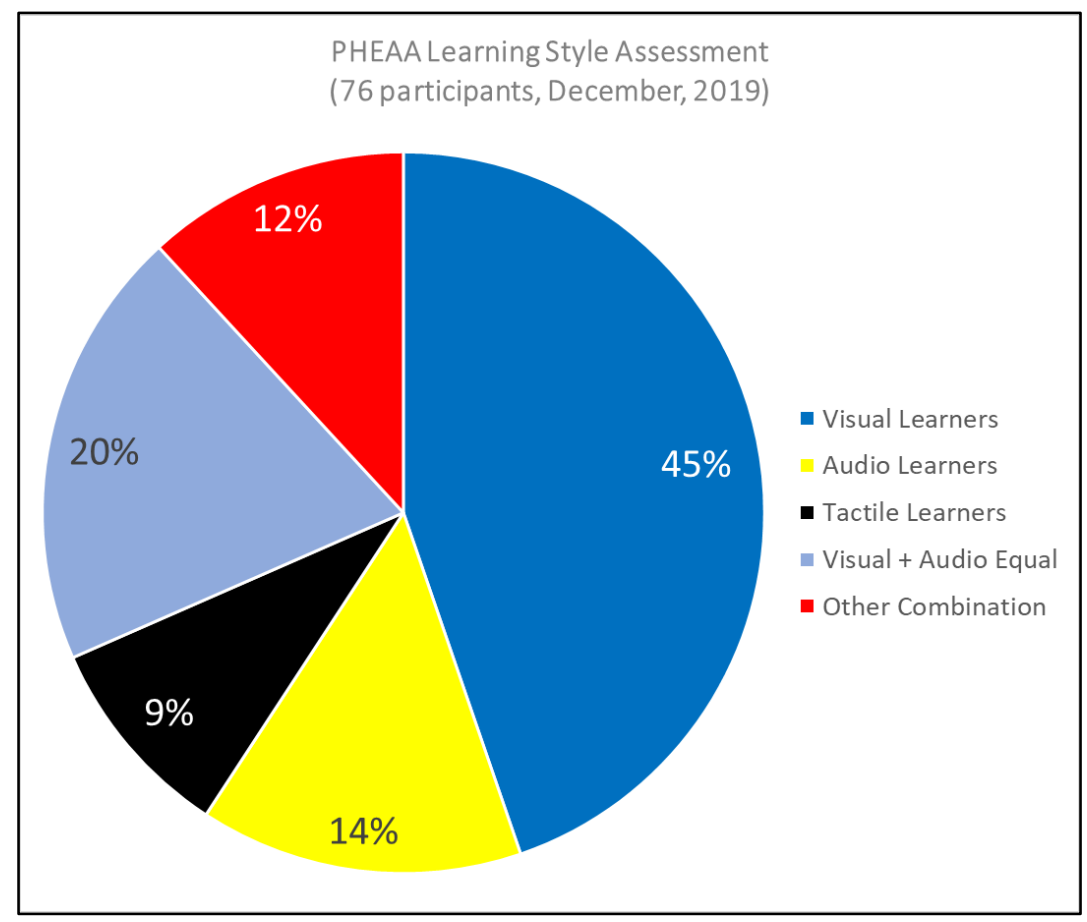

Figure 4. Pennsylvania Higher Education Assistance Agency (PHEAA) learning style assessment of 76 cadets taking EV450, December 2019.

The difficulty in this material for students with no engineering background is exemplified by the following survey response: "regardless of [the] demonstration, I'm still super lost and have no idea what's going on." Furthermore, another student though stated that "I think a lot of people need more practice...I did like seeing the demonstration; much easier to understand when you can see the real thing." Due to comments like this, efforts are being made to further improve the demonstration so it can depict the basic concepts in more detail and tie the demonstration even closer to the information presented with the energy equation.

\section{Proposed Model Changes}

In order to make the demonstration more realistic and expand on what occurs when elevation changes, an additional model is being designed to address some of the disadvantages with the simple in-class demo previously described. Clear one-inch Formufit Schedule-40 PVC will show the flow of water in an enclosed system; but, vertical tubes to simulate piezometers with a 3-way valve will also be placed throughout the pipeline to illustrate how high water will rise against gravity at different points along the system. This change demonstrates the hydraulic head measurement at any given point throughout the system that results from pressure and elevation 
changes. Next, as shown in Figure 5 a length of yarn will be used to connect the points at which water rises thus illustrating the Hydraulic Grade Line (HGL) in a physical manner. As the pressure and elevation components change, the yarn will be adjusted to visually depict the change in the HGL in real-time, so students understand the cause and effect relationships from changes in the system. PVC tubing was specifically selected as the piping material since PVC is one of the most common materials found for water conduction and transmission in smaller villages throughout developing countries. Additionally, the possibility of videoing larger scale examples that run great distances, having the instructor walking through the energy equation step-by-step while also showing the results of the actual measurements of flowrate using piezometers and pitot tubes located at various points throughout the system were also discussed.

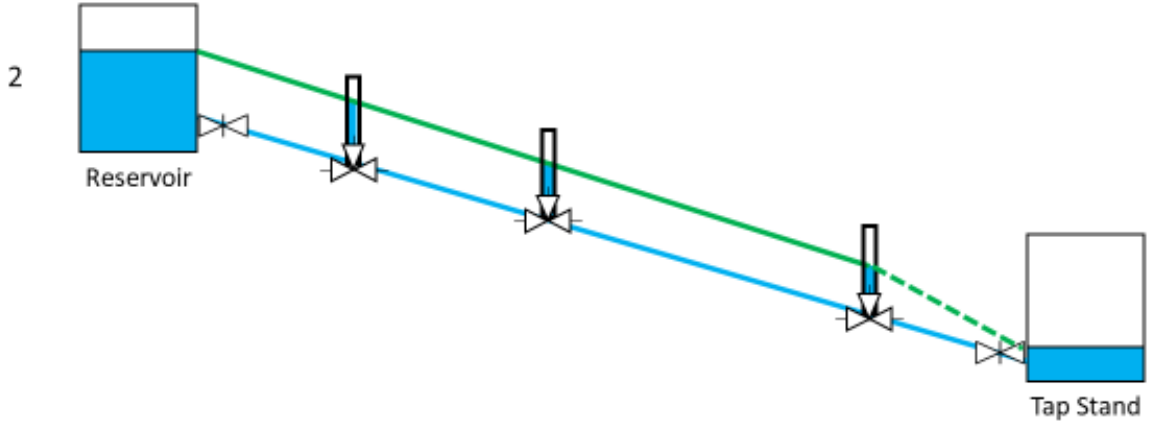

Figure 5. Additional model presenting the Hydraulic Grade Line (HGL). 


\begin{tabular}{|l|c|}
\hline \multicolumn{1}{|c|}{ Equipment } & Quantity \\
\hline 3/8” O.D. 1/4” I.D. Clear Vinyl Tubing & Multiple Lengths (5' Roll Recommended) \\
\hline 3/8” O.D. 1/4” I.D. Push-to-Connect Tee Joint & x2 \\
\hline 3/8” O.D. 1/4" I.D. Push-to-Connect Valve & x1 \\
\hline 3/8” Barbed Hose Fitting & x1 \\
\hline 1/2" $\rightarrow$ 3/8” Flare Brass Adapter & x3 \\
\hline 3/8” Hose Clamp & x1 \\
\hline 12" Tall x 16" Wide White Wood Backing & As needed \\
\hline 3/4" Thick Wood Base x 36” Wide & x1 \\
\hline 12" Tall Back Brace Supports & \\
\hline 5 Gallon Bucket &
\end{tabular}

Figure 6. Equipment needed for revised demonstration.

To collect data, specifically flowrate, a known volume of the two-liter Phipps \& Bird B-KER2 Laboratory Jar is used to measure the amount of time it takes to fill the container, which also aligns with the class concepts later introduced during natural spring development. To measure the water pressure at the tap, a low flow water pressure gauge is installed to outline pressure changes due to the change in elevation and friction. To simulate illegally tapped lines from villagers acquiring water from the water lines before it reaches the community tap stand, the 3way valves at the piezometers will be slightly adjusted to demonstrate effects of water leaving the system and therefore decreasing the overall pressure at the tap. If enough water is deviated throughout the water line before it makes its way to the tap stand, students can once again see the cause and effect relationship at the tap stand and the importance to send a message to the community members that it is a shared resource. With attached piezometers giving us the hydraulic head, and being able to measure elevation head, students can then solve for the pressure head. A pressure gauge will be used to show pressure at the effluent to validate the calculated answers as well as aid in visualizing the inputs for a Microsoft Excel Hydraulic Grade Line (HGL) builder which assists students in future design projects; or, the builder is simply a calculator that uses the Bernoulli equation and Darcy-Weisbach friction loss considerations to generate a HGL. 


\section{Conclusion}

A visual demonstration depicting the energy head equation and the forces involved in correctly designing and implementing gravity-fed water systems has successfully been used with students with a limited engineering background. Thus far, this demonstration has received generally positive feedback. Improvements to the demonstration are in progress in order to present more variables that are important to understand conceptually, as well as the variables that are used in the HGL builder. Use of the improved model, along with the Excel HGL builder, will enable students to accurately understand the engineering concepts involved in ensuring water makes it to water deprived populations. The original demonstration will still be incorporated to demonstrate the flow basics including the continuity equation, elevation head, and backpressure. Yet, the additional demonstration will be incorporated in a subsequent lesson in order to demonstrate the HGL and the effects of pressure in the system. With the two demonstrations combined, students should be able to better comprehend fluid dynamics and the subcomponents of the hydraulic grade line to determine whether or not there will be sufficient pressure delivered to the tap. 


\section{References}

1. Fetter CW. Applied Hydrogeology. Upper Saddle River (NJ): Prentice Hall; 2001.

2. Munson BR, Young DF, Okiishi TH. Fundamentals of Fluid Mechanics. New York (NY): John Wiley \& Sons, Inc.; 1998.

3. Mihelcic JR, Fry LM, Myre EA, Phillips LD, Barkdoll BD. Environmental Engineering for Development Workers. Reston (VA): ASCE Press; 2009.

4. Hemond HF, Fechner EJ. Chemical Fate and Transport in the Environment. Waltham (MA): Elsevier; 2015.

5. Education Planner.org. Harrisburg (PA): Pennsylvania Higher Education Assistance Agency; c2019 [accessed 2019 Dec 12]. http://www.educationplanner.org/students/self-assessments/ learning-styles.shtml 